\title{
El entorno actual de las relaciones políticas internacionales: sus componentes y temas de interés
}

Fecha de recepción: 15 de marzo de 2010

Fecha de aprobación: 1 junio de 2010

\author{
Iván Augusto Bonilla Puerta \\ ibonilla@poligran.edu.co \\ Politécnico Grancolombiano
}

\begin{abstract}
Reseña de autor
Especialista en Mercadeo de la Universidad EAFIT, graduado de Estudios Superiores Especializados DESS, Comercio Exterior en la Universidad de Perpignan, Francia.
\end{abstract}

\section{Resumen}

La primera parte de este artículo describe cómo las relaciones internacionales comenzaron con la Paz de Westfalia, que puso fin a la Guerra de los Treinta Años; también hace referencia a las cuatro etapas en las que se divide el estudio de este campo del saber. Después, el artículo menciona que muchos de los rasgos de las relaciones internacionales tienden a aparecer y repetirse a lo largo de la historia.

En otro apartado, explica cómo la caída de la Unión Soviética y el fin de la Guerra Fría, que ocurrieron en el contexto de una economía globalizada, redefinieron el escenario de las relaciones internacionales y contribuyeron a crear un nuevo orden internacional.

Más tarde, el artículo describe a los nuevos actores que aparecen en la escena internacional, el rol que éstos desempeñan y su manera de interactuar, motivados por nuevos factores

\section{Abstract}

The beginning of this article describes how the international relations started with the peace of Westphalia, which finished the Thirty Years War. It also mentions the four stages by which the study of this intellectual field is divided. Then the article remarks that many treats and features of International Relations tend to appear and to be repeated in history.

In other chapter, the article explains how the fall of the Soviet Union and the end of the Cold War, which occur within the new globalized economy, redefine the conditions of International Relations and created a new international order.

Then, the article describes the actors who appear on international context, the roles they play and how they interact, motivated by new factors and problems which emerge inside the new complexities of this redefined order. 
y problemas que emergen de las nuevas complejidades de este orden redefinido.

También explica cómo algunas conductas fanáticas y violentas, propias de épocas ya pasadas como la medieval, reaparecen bajo estas circunstancias.

Al final, el artículo expone las variables del sistema internacional y los temas considerados como las principales fuentes generadoras de conflicto en la actualidad, de acuerdo con Pearson y Rochester (2000), autores de uno de los más importantes textos que se han escrito sobre este tema.

\section{Palabras clave}

Estado Nación, sistema internacional, alineación ideológica, cibernética, actores no estatales, perfil psicográfico.
It also explain how some violent and fanatic behaviors, belonged to former times like the Middle Ages, reappear under these new circumstances.

At the end, the article exposes the International System's variables and the topics considered as the major sources of conflict now a days, according to Pearson and Rochester (2000), authors of one of the most important text books written about this topic.

\section{Keywords}

Nation State, International System, Ideological Alignment, Cybernetics, non-State Actors, Psychografic Profile.

\section{Introducción}

Se dice que las relaciones internacionales comienzan en 1648 con la Paz de Westfalia, que pone fin a la Guerra de los Treinta Años en Europa. Aparecen los Estados Naciones, en la forma básica en que los conocemos actualmente; también, el concepto de soberania y el de sistema internacional. Todos los sucesos anteriores a Westfalia, carecen de carácter internacional, puesto que no existían naciones y, por lo tanto, era imposible entablar relaciones entre naciones.

Es posible dividir el desarrollo histórico de las relaciones internacionales en cuatro grandes periodos. En primer lugar figura, precisamente, el periodo comprendido entre la paz de Westfalia en 1648 y la caída de la primera monarquía y de la aristocracia en la revolución francesa, que da paso a la concepción democrática y republicana del Estado en 1789 , y que se conoce como el sistema clásico internacional.

Le sigue el periodo comprendido entre 1789 y 1945, año en el que finaliza la Segunda Guerra Mundial; este periodo recibe el nombre de sistema internacional de transición.

Después, está el periodo de la posguerra o Guerra Fría, que se extiende 
desde 1945 hasta 1989, con la caída del muro de Berlín. Por último, aparecen los acontecimientos que se desarrollan a partir de 1989, periodo conocido como sistema contemporáneo o posterior a la Guerra Fría.

No obstante, desde la Antigüedad, la forma en que se desenvolvían las relaciones entre grupos culturales -babilonios; judíos y egipcios; aqueos, troyanos, hititas y helenos; chinos y mongoles; macedonios y griegos; griegos y romanos; musulmanes y cristianos; serbios y austrohúngaros; otomanos, serbios, $\mathrm{y}$ árabes; moros y españoles; europeos con mongoles; tártaros y chinos; españoles y aztecas; mayas, muiscas e incas; o cualquier otra combinación de la extensa lista de posibilidades- entrañan raíces de las que se originan muchos de los conflictos actuales en el ámbito de las Relaciones Internacionales; el conflicto de los Balcanes, por ejemplo, se remonta a seiscientos años atrás. $\mathrm{Mu}-$ chos de los rasgos de dichos conflictos se reproducen o tienden a repetirse.

A la luz de la coyuntura actual, el campo de las relaciones internacionales y de las relaciones políticas internacionales adquiere un carácter cada vez más amplio e indefinido, en vista de la globalización que origina interdependencia.

La reacomodación y redefinición del escenario geopolítico mundial, a raíz de la caída del bloque soviético, trajo como consecuencia la imposibilidad de identificar a los actores que integraban la escena política, cuya acción se limitaba a los Estados Naciones.

Cuando las relaciones internacionales se enmarcaban en la Guerra Fría, el mundo se polarizaba bajo la orientación de las dos grandes potencias y, por lo tanto, dentro de tales relaciones antagónicas. La claridad del escenario era indiscutible, el entorno político más estable y el enemigo claramente identificable.

Estas condiciones equilibraban las relaciones internacionales; pero, una vez desmembrado el bloque soviético, las naciones alineadas a su ideología -e incluso muchas que no se consideraban dentro de esta órbita o culturas y grupos de diversos orígenes o nacionalidades- encontraron formas alternativas de concebir el Estado, la sociedad y la democracia.

Estos elementos, asociados a la desaparición de la confrontación ideológica bipolar, crearon las condiciones para revivir antiguos conflictos raciales, religiosos, nacionalistas y de múltiples naturalezas y orígenes.

Asimismo, el acceso al desarrollo y la obtención de armas no convencionales -armas ABC-, se hizo cada vez más fácil: en unos casos, porque los países que pertenecieron a la antigua Unión Soviética ya las poseían; y en otros, como consecuencia de la apertura de fronteras y del avance de tecnologías de comunicación, informática, telemática y cibernética.

El modelo económico impuesto por la globalización, como lo demuestra 
la realidad tanto en países desarrollados como en los subdesarrollados, genera pobreza y exclusión, sobretodo en estos últimos. Este modelo se convirtió en otra causa de conflictos y, en consecuencia, la bipolaridad Este-Oeste encuentra espacios y matices de expresión en la bipolaridad Norte-Sur, pese a no contar con características de confrontación claras, como las de la rivalidad Este-Oeste durante la Guerra Fría.

Esto se evidencia en que los principales orígenes del terrorismo se encuentran en los países del tercer mundo, debido a los resentimientos generados por varios siglos de dominación colonialista europea en Asia, África y Latinoamérica. Odios y resentimientos exacerbados por la actitud imperial e intervensionista de los Estados Unidos, desde el momento en que, inspirados en la Doctrina Monroe -1823-, el Destino Manifiesto -1845y el Corolario Roosevelt -1904-, orientaron sus intereses y su política internacional hacia el expansionismo a través de la intervención.

Es posible que las raíces de algunos de estos conflictos no estén directamente relacionadas con el dominio colonial de países europeos sobre otros, pero por lo general residen en el dominio que, por motivos raciales o religiosos, una potencia ejerció sobre otra raza, cultura, estado o nación.

Es el caso del conflicto de Irlanda e Inglaterra y también el de los Balcanes, originado en el dominio que el imperio Otomano ejerció sobre esta región hace muchos años, cuya reacción fue una actitud y política de odio y limpieza racial contra los bosnios y kosovares, racismo que encontró eco en el odio y la confrontación del cristianismo europeo y el islamismo árabe y otomano.

Este panorama también se vive en el sangriento conflicto entre los utú y los tutsi, de Rwanda y Bururndí; los ausa y yarubá, de Nigeria; o el problema de Cachemira en la India, de los cuales el más representativo es el de los Balcanes, pese a que el régimen de Josip Broz Titolo lo mantuvo adormecido en torno a una unidad nacional, ideológica y política, pero que tras su deceso -y la coincidente desaparición de la Guerra Fría y el bloque soviético- estalló con las cruentas consecuencias por todos conocidas.

Cuando colapsa la Unión Soviética, sólo queda un gran poder en la esfera internacional. Esta cualidad de único lo hace mucho más dominante y arrogante y, por lo tanto, unilateral en sus decisiones, lo que exacerba los odios contra él, y crea un círculo vicioso de inestabilidad y conflictos con motivos más fuertes para tornarse paranoico, pues debe defenderse de un enemigo desconocido o difícil de identificar; como en el atentado del Edificio Federal de Oklahoma City, ataque que provino del interior mismo de la nación, de los grupos ultraderechistas y racistas neonazis y de la autodenominada supremacía blanca. 
Algunos movimientos terroristas, surgen como resultado de conflictos internos de las naciones, por razones de índole racial, religiosa o política, o porque uno de los bandos se ha aliado en -el pasado o en el presente- con los intereses de alguna potencia extranjera, - cuando los nazis invadieron Yugoslavia, por ejemplo, los croatas se aliaron con quienes cometían todo tipo de atrocidades contra los serbios-, o por viejas razones inmersas en el pasado colonial, o porque a la luz del entorno político actual, los intereses de los actores, entre ellos las grandes potencias, trascienden las fronteras nacionales.

Por estas razones, los Estados $\mathrm{Na}^{-}$ ciones ya no son únicos actores que intervienen en la escena de las Relaciones Internacionales, sino que en del contexto actual, éstos han proliferado en diversas formas que trascienden la simple categoría de Estado Nación. Nos encontramos entonces ante una escena política, tan heterogénea como inestable e impredecible. Los grupos de ultraderecha racista de los Estados Unidos que cometieron el atentado de Oklahoma City fueron asesorados por el grupo fundamentalista islámico de Filipinas Abhu Sayá, en razón del sentimiento antisemita que tienen en común.

Los actores provienen de ONGS o incluso de grupos terroristas, guerrilleros, carteles y agremiaciones cuyas actividades y objetivos tienen un carácter legítimo, aunque se encuentren al margen de la ley, pero que ejercen algún tipo de poder o capacidad de presión, y a quienes la comunidad internacional se ha visto obligada a reconocer. Estos son los actores no estatales.

En estas circunstancias, las relaciones internacionales ya no se desarrollan solamente entre estados, sino también entre dichos actores no estatales y los estados, y entre estos actores no estatales entre sí. A partir de este punto surge otro elemento vital para la conformación de la escena de las relaciones internacionales actuales: la trascendencia y el límite entre los fenómenos y las decisiones externas y las internas o domésticas.

En este contexto, sucesos tan dramáticos como los atentados perpetrados por la organización Al Qaeda a las embajadas norteamericanas de Nairobi y Dar-Es-Salam, y los del 11 de septiembre de 2001, son episodios que sintetizan y reflejan el entorno político generado por la globalización.

Todos conocemos los orígenes de Al Qaeda, apoyada por los talibanes afganos, herederos del conflicto armado afgano soviético, uno de los escenarios más cruentos de la Guerra Fría. Es posible hacer la misma consideración sobre el conocido -y macondiano- suceso del submarino descubierto en Facatativá hace algunos años, en el cual convergen todos los componentes que configuran la escena política global actual; hoy los submarinos incautados a los carteles emergentes hacen parte 
del panorama cotidiano de las noticias relacionadas con el narcotráfico.

Dentro del unilateralismo que caracteriza al entorno político internacional actual, se debe considerar que el papel que juega la onu, en la resolución de los conflictos internacionales es cada vez más débil, pues ha cedido su espacio y su protagonismo a la OTAN, organismo de carácter fundamentalmente militar.

Este nuevo enfoque del papel de los organismos multilaterales, responde al carácter inestable del entorno político mundial, que genera el deterioro de la gobernabilidad de países subdesarrollados, originado por la aplicación incondicional de las medidas de ajuste económico, necesarias para insertar a los países en el proceso de internacionalización de las economías y los mercados, como los casos de Argentina, Ecuador, Perú; o bien, por lo contrario, es decir los países cuyos gobiernos manifiestan claras reticencias a implantar este tipo de medidas, inevitablemente comienzan a mostrar graves problemas de gobernabilidad, como en algún momento ocurrió con Venezuela; y son inmediatamente señalados, con razón o sin ella, como un factor de inestabilidad regional o mundial.

A esta tendencia de un cambio de rol de los organismos y los foros multilaterales de concertación política y económica, se puede agregar el resurgimiento de un sentimiento tercer mundista, por ejemplo en los casos como los de Venezuela con Hugo Chávez, Bolivia con Evo Morales, el de Irán con su programa de enriquecimiento de uranio, Corea del Norte desarrollando fuentes de poder nuclear, y muchos otros que expresan de una manera más ajustada al contexto actual; ese movimiento contestatario y desafiante que en la década de los cincuenta, se materializó con la Liga de los Países No Alineados, liderado por figuras como Tito, Nasser, Suharno y Nehrú, como una forma de deslindarse de la confrontación EsteOeste de ese entonces; pero que con la actual coyuntura adquiere una nueva orientación y nuevo talante.

La desaparición de las ideologías es otro de los fenómenos que aparentemente caracterizan la escena política del mundo globalizado. Lo anterior, se sustenta bajo la idea de que la globalización misma es el predominio y la preponderancia de una ideología como el capitalismo en su expresión más intensificada, acentuada y extendida, con el eufemismo con el que actualmente se le denomina como economía de mercado. Es más, si se analiza la recomposición del escenario electoral en el mundo, se puede apreciar que si bien es cierto, en algunos países, entre ellos los de la antigua cortina de hierro, algunos partidos socialdemócratas, e inclusive los mismos partidos comunistas, obtienen algún repunte y figuración; el fenómeno electoral del mundo muestra, en 
algunos países, una marcada tendencia hacia la derecha e incluso, a la extrema derecha como es el caso colombiano. Si bien el fenómeno ya no se expresa en falangismos como el español de Franco, ni en fascismos como el chileno de Pinochet, sí persisten o renacen expresiones como los neonazis en Europa y en Estados Unidos, y todo tipo de movimientos y tendencias de derecha o extrema derecha de orientación xenófoba y racista en países como Francia, Austria, y la mayoría de los países europeos, así como los fenómenos paramilitares que como en el caso colombiano, se han convertido en un verdadero reciclaje de carteles de narcotraficantes.

Esta derechización del mundo, puede no ser tan evidente, en razón de la creencia de que con el fin de la Guerra Fría, y con la aparición de la globalización, desaparecieron sus corrientes. Una ideología es fundamentalmente una actitud ante la vida y las cosas, y el reflejo de un perfil psicográfico, -de hecho, los perfiles psicográficos se miden con escalas actitudinales y de valores-. Se puede encontrar fácilmente un ciudadano y consumidor que poco se interese por los temas políticos y por las ideologías; pero si su interés es el de consumir ante todo, o sobrevivir consumiendo con seguridad; y en las actuales circunstancias, la vida de los ciudadanos se reduce exclusivamente casi a su dimensión consumista; en los momentos de tener que decidir por una opción política, será más proclive a hacerlo por aquella que refleje y represente su interés individual y le proponga las opciones y alternativas más cómodas, seguras y que más se acomoden a su única dimensión de consumidor. Estas opciones las encarnan los partidos de derecha en todo el mundo.

Siendo la eficiencia, la productividad, y el consumo, entre otros, los ejes generadores del esquema económico globalizado, lo que podrá prevalecer entonces es una tendencia hacia una pensée unique, como la han denominado los politólogos franceses y que ampliamente vaticinó Aldoux Huxley en su libro Brave New World -Un mundo feliz-Por esto mismo es que el deterioro de ciertos partidos políticos de derecha, no consiste realmente en un proceso de desaparición, sino más bien, en una metamorfosis, una transformación, un realinderamiento, una reacomodación y reaglutinamiento de las fuerzas ideológicas que encarnan la globalización y las corrientes neoliberales en lo económico; en los nuevos movimientos políticos que se ajustan a esta naciente coyuntura.

No obstante, en los últimos años este fenómeno de derechización ha encontrado un escenario adverso en el cual se ha revertido, como es el caso de Suramérica, y que con excepción de Colombia tiende a extenderse a lo largo de Latinoamérica, con el nuevo auge característico de los partidos socialdemócratas y de izquierda, los cuales han llegado al poder o que en el peor de los casos, muestran poseer 
la suficiente fuerza electoral como para poner en jaque a gobiernos de derecha en la región.

Este resurgimiento de la izquierda, inesperado para algunos, es un reflejo del fracaso de las políticas de ajuste del consenso de Washington y el FMI, con las cuales se implantó de una manera coactiva, la ideología y el modelo económico neoliberal de la globalización.

Otro aspecto que surge a partir de la reacomodación y el surgimiento de este nuevo escenario, es el relacionado con carácter exclusivo y unidisciplinario de las relaciones internacionales, pues es claro que éstas ya no se circunscriben sólo al plano político, sino que inevitablemente invaden las fronteras de lo económico, lo tecnológico, lo cultural, lo ecológico y de otras dimensiones que atañen directamente con la vida de las diferentes sociedades, culturas y estados naciones.

Otro elemento a tener en cuenta en de la nueva forma de abordar el estudio de las relaciones internacionales, es la metodología de estudio. Al respecto, Pearson y Rochester, (2000, p. 26), mencionan cuatro formas de análisis:

1. La descriptiva.

2. La explicativa.

3. La normativa.

4. La prescriptiva.

Estas maneras de entender el estudio de las relaciones internacionales desarrollan las interpretaciones y el análisis de las mismas, de acuerdo con la idea y acepción que implican sus nombres, utilizados y adoptados indiscriminadamente, tanto por expertos como por el más corriente de los ciudadanos.

Sobre los elementos y variables del sistema internacional, Pearson y Rochester (2000, p. 38) mencionan las siguientes:

1. Naturaleza de los actores, es decir, actores estatales y no estatales.

2. Distribución del poder, que se refiere al equilibrio entre los diferentes actores y el dominio o predominio que puedan ejercer unos sobre otros.

3. Distribución de la riqueza, el grado de polarización y de alianza entre los diferentes actores.

4. Intereses y propósitos de los actores.

5. Recursos y medios que los diferentes actores poseen para desarrollar sus políticas, satisfacer sus intereses y lograr sus propósitos.

Grado de interdependencia reflejado en el comercio de bienes y servicios, los flujos y movimientos migratorios, los flujos de comunicaciones y la vulnerabilidad de los actores.

Las transformaciones que estas variables han sufrido como consecuencia del cambio y redefinición del escenario, son sustanciales y definen el entorno político internacional de la globalización.

Existe una amplia diversidad de temas generadores de conflictos en el 
campo de las relaciones internacionales, Pearson y Rochester (2000, p. 29) los aglutinan en siete, considerados de mayor prioridad e importancia, estos son: el control de armas; el terrorismo y otros tipos de violencia; la regulación de la economía y el comercio internacional; los problemas relativos al crecimiento y el desarrollo económico; el de la inmigración y el desplazamiento, originado tanto en complicaciones económicas, como en conflictos políticos que se agudizan; los derechos humanos; $y$, por último, el manejo, uso y administración de los recursos naturales y el medio ambiente.

A la luz de los análisis realizados, es claro que estos temas ofrecen una evidente e indiscutible interdependencia; y, por esta razón, contribuyen en la generación de interdependencia entre los diferentes actores del escenario político internacional, interdependencia que caracteriza el fenómeno actual de la globalización.

\section{Discusión}

La escena política internacional de hoy es el resultado de la interacción continuada de todos los sucesos y conflictos del pasado. No se interrumpe. La historia funciona siempre así. Entonces, es imposible entender el presente si no se conoce el pasado.

Por otra parte, los medios de comunicación y las nuevas tecnologías de información y comunicación -TICs-, como punta de lanza de esta sociedad global y de las grandes compañías transnacionales, difunden una cultura de masas que produce ciudadanos cada vez más y mejor informados para consumir, pero con un sentido y una actitud cada vez menos crítica y más superficial respecto a sí mismo y a su entorno, pues se orienta hacia lo visual y se aleja de lo reflexivo.

Es innegable que estas nuevas TICs promueven una revolución en todos los niveles de esta sociedad. Han contribuido y continuarán incidiendo en dar forma a este escenario tan caótico e impredecible.

Queda entonces por abordar una nueva discusión, planteada por Manuel Castels, sobre un ciudadano global integrado y al mismo tiempo aislado por obra de estas Tics.

\section{Referencias}

1. Kegley $\mathrm{CH}_{\mathrm{Jr}}$ \& wittkopf, E.R. (2001).World Politics, Trend and Transformation. (8 Ed.). Boston: Bedford/Saint Martin's.

2. pearson F.S. y rochester J.M. (2000). Relaciones Internacionales, situación global en el siglo XXI. (1 Ed.). Bogotá: McGraw-Hill Interamericana. 